OPEN ACCESS

Edited by:

Manuel González-Guerrero, Universidad Politécnica de Madrid,

Spain

Reviewed by:

David G. Mendoza-Cozatl, University of Missouri, United States

Akiko Maruyama-Nakashita,

Kyushu University, Japan

*Correspondence: Fabio F. Nocito

fabio.nocito@unimi.it

Specialty section:

This article was submitted to

Plant Nutrition,

a section of the journal

Frontiers in Plant Science

Received: 28 February 2017 Accepted: 08 May 2017

Published: 22 May 2017

Citation:

Ferri A, Lancilli C, Maghrebi M, Lucchini G, Sacchi GA and Nocito FF (2017) The Sulfate Supply

Maximizing Arabidopsis Shoot Growth Is Higher under Long- than Short-Term Exposure to Cadmium. Front. Plant Sci. 8:854. doi: 10.3389/fpls.2017.00854

\section{The Sulfate Supply Maximizing Arabidopsis Shoot Growth Is Higher under Long- than Short-Term Exposure to Cadmium}

\author{
Alessandro Ferri', Clarissa Lancilli, ${ }^{1,2}$, Moez Maghrebi ${ }^{1}$, Giorgio Lucchini', \\ Gian Attilio Sacchi ${ }^{1}$ and Fabio F. Nocito ${ }^{1 *}$ \\ ${ }^{1}$ Dipartimento di Scienze Agrarie e Ambientali - Produzione, Territorio, Agroenergia, Università degli Studi di Milano, Milano, \\ Italy, ${ }^{2}$ Istituto d'Istruzione Superiore di Codogno, Codogno, Italy
}

The processes involved in cadmium detoxification in plants deeply affect sulfate uptake and thiol homeostasis and generate increases in the plant nutritional request for sulfur. Here, we present an analysis of the dependence of Arabidopsis growth on the concentration of sulfate in the growing medium with the aim of providing evidence on how plants optimize growth at a given sulfate availability. Results revealed that shortterm (72 h) exposure to a broad range of Cd concentrations $(0.1,1$, and $10 \mu \mathrm{M})$ inhibited plant growth but did not produce any significant effects on the growth pattern of both shoots and roots in relation to the external sulfate. Conversely, long-term (22 days) exposure to $0.1 \mu \mathrm{M}$ Cd significantly changed the pattern of fresh weight accumulation of the shoots in relation to the external sulfate, without affecting that of the roots, although their growth was severely inhibited by Cd. Moreover, under long-term exposure to $\mathrm{Cd}$, increasing the sulfate external concentration up to the critical value progressively reduced the inhibitory effects exerted by $\mathrm{Cd}$ on shoot growth, indicating the existence of sulfate-dependent adaptive responses protecting the shoot tissues against Cd injury. Transcriptional induction of the high-affinity sulfate transporter genes (SULTR1; 1 and SULTR1; 2) involved in sulfate uptake by roots was a common adaptive response to both short- and long-term exposure to $\mathrm{Cd}$. Such a response was closely related to the total amount of non-protein thiols accumulated by a single plant under short-term exposure to $\mathrm{Cd}$, but did not showed any clear relation with thiols under long-term exposure to $\mathrm{Cd}$. In this last condition, Cd exposure did not change the level of non-protein thiols per plant and thus did not alter the nutritional need for sulfur. In conclusion, our results indicate that long term-exposure to $\mathrm{Cd}$, although it induces sulfate uptake, decreases the capacity of the Arabidopsis roots to efficiently absorb the sulfate ions available in the growing medium making the adaptive response of SULTR1; 1 and SULTR1; 2 "per se" not enough to optimize the growth at sulfate external concentrations lower than the critical value.

Keywords: Arabidopsis thaliana, cadmium, sulfate uptake, sulfate critical concentration, thiols 


\section{INTRODUCTION}

Plants have evolved a complex network of adaptation mechanisms that allow them to minimize the damage from exposure to non-essential and potentially toxic metal ions (Clemens, 2001, 2006). Such mechanisms involve transport, chelation, and sequestration processes controlling metal homeostasis into the cells and throughout the whole plant.

The synthesis of cysteine (Cys)-rich metal binding peptides such as phytochelatins (PCs) - appears as the most conserved and ubiquitous process used by plants for cadmium (Cd) detoxification. PCs are a class of small peptides consisting of repeating units of $\gamma$-glutamylcysteine ( $\gamma$-Glu-Cys) followed by a $\mathrm{C}$-terminal glycine (Gly): the general structure of these peptides is ( $\gamma$-Glu-Cys) ${ }_{n}$-Gly, where $n=2$ to 11 (Grill et al., 1987; Zenk, 1996; Cobbett, 2000; Cobbett and Goldsbrough, 2002), although PC2-PC4 are the most commonly detected PCs in both root and leaf tissues of Arabidopsis (Chen et al., 2006). The presence of $\gamma$-glutamyl linkages in these peptides implies that they are non-translationally synthesized using reduced glutathione (GSH) as the direct precursor in a transpeptidation reaction catalyzed by the enzyme PC synthase (Rea et al., 2004; Rea, 2006). Once synthetized in the cytoplasm, PCs form thiolate bonds with $\mathrm{Cd}^{2+}$ ions, and the resulting Cd-PC complexes are subsequently sequestered to the vacuole through multiple ABC-type transporters (Cobbett, 2000; Verbruggen et al., 2009; Mendoza-Cózatl et al., 2010; Park et al., 2012; Song et al., 2014; Brunetti et al., 2015).

In this way cells may control the concentration of the free $\mathrm{Cd}^{2+}$ ions in the cytosol, limiting the potential damage due to their overaccumulation. The relevance of this mechanism for the natural $\mathrm{Cd}$ tolerance of the plants has been underlined by the analysis of the Arabidopsis PC-deficient mutants cad 1 and cad2-1, which were more sensitive to $\mathrm{Cd}$ than wild-type plants (Howden et al., 1995a,b).

The interactions between $\mathrm{Cd}$ accumulation and sulfur (S) metabolism in higher plants have been exhaustively described and reviewed in several papers (Nocito et al., 2002, 2007; Mendoza-Cózatl et al., 2005; Ernst et al., 2008; Jozefczak et al., 2014; Lancilli et al., 2014; Khan et al., 2016). In particular, it has been shown that the increases in the metabolic request for both Cys and GSH - generated by Cd-induced PC biosynthesis produce a demand-driven coordinated transcriptional regulation of genes involved in sulfate uptake, sulfate assimilation and GSH biosynthesis. Such an activation is thought to be pivotal for ensuring - at least in the early phases of $\mathrm{Cd}$ accumulation both GSH homeostasis and adequate fluxes of reduced $\mathrm{S}$ to help $\mathrm{Cd}$ detoxification processes. In fact, the large amount of PCs produced following Cd exposure may generate additional sinks for thiols which, in turn, increase the total nutritional demand for S by plants. However, some aspects of this model need to be further elucidated, since it is not clear whether the early adaptive responses to $\mathrm{Cd}-$ involving the $\mathrm{S}$ assimilation pathway - are sufficient to maintain adequate $S$ levels to promote plant growth under prolonged exposures to the metal, i.e., whether plants growing in the presence of $\mathrm{Cd}$ need a higher amount of $\mathrm{S}$ in the soil to maximize their growth. In fact the activation of GSH consuming activities due to Cd chelation may in turn reduce the GSH-related antioxidant capacity of the cells, generating further additional requests for thiols and, thus, for $\mathrm{S}$. Considering these aspects, here we present and discuss two sets of experiments aimed at studying the effect of both short- and long-term exposure to $\mathrm{Cd}$ on the capability of Arabidopsis for optimizing growth under a wide range of sulfate concentrations in the growing medium, and showing that long-term exposure to Cd negatively affects this trait.

\section{MATERIALS AND METHODS}

\section{Plant Materials, Growth Conditions, and Experimental Design}

Arabidopsis thaliana (Ler-0) seeds were washed under continuous shaking in $0.5 \mathrm{~mL} 0.01 \%(\mathrm{v} / \mathrm{v})$ Tween 20 for $20 \mathrm{~min}$, surfacedsterilized by adding an equal volume of commercial bleach ( $4 \%$ active chlorine) for $5 \mathrm{~min}$, and then rinsed four times with sterile distilled water. Seeds were sown on a sterile $3 \mathrm{M}^{\mathrm{TM}}$ paper sheet imbibed with sterile distilled water and laid down into a Petri dish - and then incubated for 4 days, in the dark, at $4^{\circ} \mathrm{C}$ to remove dormancy.

Vernalized seeds were sown, with a toothpick, on small pieces of rockwool $\left(\right.$ Grodan $\left.^{\circledR}\right)$ placed into appropriate seed holders, obtained by cutting $1 \mathrm{~mL}$ pipette tips at 2 and $12 \mathrm{~mm}$ from the tip. The seed holders were transferred into pipette tip boxes, filled with distilled water - to maintain the rockwool imbibed and finally incubated at $22^{\circ} \mathrm{C}$ under continuous light to allow seed germination. Seven days after sowing, seedlings - selected for uniform growth - were transferred into $3 \mathrm{~L}$ plastic tanks (41 seedlings per tank) containing non-sterile aerated complete nutrient solutions and kept for 22 days in a growth chamber maintained at $22^{\circ} \mathrm{C}$ and $80 \%$ relative humidity, with a 12 -h light period.

For the short-term $\mathrm{Cd}$ exposure experiments, plants were grown for 19 days in hydroponic solutions $\left[250 \mu \mathrm{M} \mathrm{NH}_{4} \mathrm{H}_{2} \mathrm{PO}_{4}\right.$, $1.5 \mathrm{mM} \mathrm{KNO}_{3}, 1 \mathrm{mM} \mathrm{Ca}\left(\mathrm{NO}_{3}\right)_{2}, 25 \mu \mathrm{M}$ Fe-tartrate, $46 \mu \mathrm{M}$ $\mathrm{H}_{3} \mathrm{BO}_{3}, 9 \mu \mathrm{M} \mathrm{MnCl}_{2}, 0.8 \mu \mathrm{M} \mathrm{ZnCl}, 0.3 \mu \mathrm{M} \mathrm{CuCl}_{2}, 0.1 \mu \mathrm{M}$ $\left(\mathrm{NH}_{4}\right)_{6} \mathrm{Mo}_{7} \mathrm{O}_{24}, \mathrm{pH}$ 6.5] with different sulfate concentrations $\left.(5,25,50 \text {, and } 150 \mu \mathrm{M} \mathrm{MgSO})_{4}\right)$. At the end of this pre-growing period plants were maintained in the same solutions and exposed, or not, to three concentrations of $\mathrm{Cd}^{2+}\left(0.1,1\right.$, and $\left.10 \mu \mathrm{M} \mathrm{CdCl}_{2}\right)$ for $72 \mathrm{~h}$.

For the long-term $\mathrm{Cd}$ exposure experiments plants were grown for 22 days in hydroponic solutions $\left[250 \mu \mathrm{M} \mathrm{NH}_{4} \mathrm{H}_{2} \mathrm{PO}_{4}\right.$, $1.5 \mathrm{mM} \mathrm{KNO}_{3}, 1 \mathrm{mM} \mathrm{Ca}\left(\mathrm{NO}_{3}\right)_{2}, 25 \mu \mathrm{M}$ Fe-tartrate, $46 \mu \mathrm{M}$ $\mathrm{H}_{3} \mathrm{BO}_{3}, 9 \mu \mathrm{M} \mathrm{MnCl}_{2}, 0.8 \mu \mathrm{M} \quad \mathrm{ZnCl}_{2}, 0.3 \mu \mathrm{M} \mathrm{CuCl}_{2}$, $0.1 \mu \mathrm{M}\left(\mathrm{NH}_{4}\right)_{6} \mathrm{Mo}_{7} \mathrm{O}_{24}, \mathrm{pH}$ 6.5] under a wide range of sulfate concentrations $(1,2.5,5,7.5,10,25,50,75,100,125$, and $150 \mu \mathrm{M}$ $\mathrm{MgSO}_{4}$ ), in the presence or absence of $0.1 \mu \mathrm{M} \mathrm{CdCl}_{2}$.

In all the experiments, $\mathrm{MgCl}_{2}$ was added to maintain the same concentration $(500 \mu \mathrm{M})$ of the $\mathrm{Mg}^{2+}$ ions in each solution. All hydroponic solutions were renewed daily to minimize sulfate depletion. At the end of the growing periods, plants were used for the in vivo experiments or harvested to be further analyzed. In this case, roots were washed for $10 \mathrm{~min}$ in an ice-cold $5 \mathrm{mM}$ 
$\mathrm{CaCl}_{2}$ solution to displace extracellular Cd (Rauser, 1987), rinsed in distilled water and gently blotted with paper towels; shoots were separated from roots and the tissues were weighed before to being frozen in liquid $\mathrm{N}_{2}$ and stored at $-80^{\circ} \mathrm{C}$.

\section{Plant Growth Analysis}

The curves describing the growth of both shoots and roots as a function of the sulfate concentration in the growing medium were drawn by fitting an exponential rise to maximum function to the data obtained by weighing the shoots and the roots of the Arabidopsis plants at the end of each experiment (Zhao et al., 1999). To this purpose, we chose a three-parameter exponential curve with the formula:

$$
y=y_{0}+a\left(1-e^{-b x}\right)
$$

where $y$ is the fresh weight (FW), $y_{0}$ is the FW offset from $\left[\mathrm{SO}_{4}{ }^{2-}\right]=0, a$ is the amplitude of the curve (i.e., the difference between the maximum and the minimum value of the FW), $b$ is the rate constant, $x$ is the sulfate concentration in the medium.

The sulfate critical concentration $\left(\left[\mathrm{SO}_{4}{ }^{2-}\right]_{\text {crit }}\right)$ - defined as the sulfate concentration in the growing medium that produced $95 \%$ of the maximum amount of fresh weight for shoots or roots - was calculated in each experiment as follows:

$$
\left[\mathrm{SO}_{4}^{2-}\right]_{\text {crit }}=\frac{\log _{\mathrm{e}}\left[\frac{0.05\left(y_{0}+a\right)}{a}\right]}{-b} .
$$

\section{Determination of Total Sulfur, Thiols, and Cadmium Content}

Shoots and roots were pulverized using mortar and pestle in liquid $\mathrm{N}_{2}$. Total sulfur contents were determined according to the turbidimetric method described by Tabatabai and Bremner (1970). Total non-protein thiols (NPTs) and Cd contents were determined as described by Fontanili et al. (2016). Total GSH, reduced GSH and oxidized GSH (GSSG) were measured according to Griffith (1980). PCs and related peptides (nonGSH NTPs) were estimated as the difference between NPT and total GSH levels in both shoots and roots of Cd-exposed plants (Sghayar et al., 2015).

\section{Sulfate Influx Assay}

Sulfate influx into the roots was measured by determining the rates of ${ }^{35} \mathrm{~S}$ uptake, over a $15 \mathrm{~min}$ pulse in a complete nutrient solution labeled with the radiotracer. Briefly, a single plant was placed onto $10 \mathrm{~mL}$ of a fresh acclimation nutrient solution with the same ionic composition as those used for plant growth, containing $150 \mu \mathrm{M} \mathrm{MgSO}$, supplemented or not with different concentrations of $\mathrm{CdCl}_{2}\left(0.1,1\right.$, and $10 \mu \mathrm{M} \mathrm{Cd}^{2+}$ for the shortterm exposure experiments; $0.1 \mu \mathrm{M} \mathrm{Cd}^{2+}$ for the long-term exposure experiments); each solution was maintained aerated and thermoregulated at $22^{\circ} \mathrm{C}$. Radioactive pulses were started by adding ${ }^{35} \mathrm{~S}$-labeled $\mathrm{Na}_{2} \mathrm{SO}_{4}$ to the uptake solutions. Specific

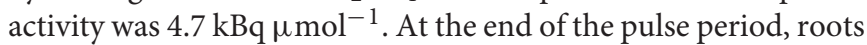
were rinsed twice for $1 \mathrm{~min}$ in $10 \mathrm{~mL}$ of a $4 \mathrm{mM} \mathrm{CaSO}_{4}$ nonradioactive solution at $4^{\circ} \mathrm{C}$, blotted with paper towels, weighed, and then heated for $20 \mathrm{~min}$ at $80^{\circ} \mathrm{C}$ in $5 \mathrm{~mL} 0.1 \mathrm{~N} \mathrm{HNO}_{3}$.
Radioactivity was measured on aliquots of the extracting solution by liquid scintillation counting in a $\beta$ counter (LS 6000SC, Beckman).

\section{RNA Extraction and qRT-PCR Analysis}

Total RNA was extracted from roots using TRIzol ${ }^{\circledR}$ Reagent (Life Technologies) and then purified using PureLink ${ }^{\circledR}$ RNA Mini Kit (Life Technologies), according to the manufacturer's instructions. Contaminant DNA was removed on-column using PureLink ${ }^{\circledR}$ DNase (Life Technologies). First-strand cDNA synthesis was carried out using the SuperScript ${ }^{\text {TM }}$ III First-Strand Synthesis SuperMix for qRT-PCR (Invitrogen), according to the manufacturer's instructions.

qRT-PCR analysis of SULTR1; 1 (At4g08620) and SULTR1; 2 (At1g78000) was performed on first-strand cDNA in a $20 \mu \mathrm{L}$ reaction mixture containing GoTaq $^{\circledR}$ qPCR Master Mix (Promega) and the specific primers, using an ABI 7300 Real-Time PCR system (Applied Biosystems). The relative transcript level of each gene was calculated by the $2^{-\Delta \Delta \mathrm{Ct}}$ method using the expression of the S16 (At4g34620) gene as reference. Primers for qRT-PCR are listed in Supplementary Table S1.

\section{Statistical Analysis}

Statistical analysis was carried out using SigmaPlot for Windows version 11.0 (Systat Software, Inc.). Quantitative values are presented as mean \pm standard error of the mean (SE). Significance values were adjusted for multiple comparisons using the Bonferroni correction. Student's $t$-test was used to assess the significance of the observed differences between control and Cd-exposed plants. In both cases, statistical significance was at $P<0.05$.

\section{RESULTS}

\section{Effect of Short-Term Exposure to Cd under Different Sulfate Concentrations on Growth, Thiol Content, Cd Accumulation, and Sulfate Uptake of Arabidopsis Plants}

For short-term experiments, Arabidopsis plants were pre-grown for 19 days under four different sulfate concentrations $(5,25,50$, and $150 \mu \mathrm{M})$ and then exposed for $72 \mathrm{~h}$ to three concentrations of $\mathrm{Cd}^{2+}(0.1,1$, and $10 \mu \mathrm{M})$. For each $\mathrm{Cd}$ concentration used in the experiments, we produced a set of curves showing the dependence of shoot (Figure 1A) or root (Figure 1B) fresh weight on the sulfate availability in the growing medium. All the curves - properly described by exponential rise to maximum functions - approached saturation (95\% of the maximum amount of fresh weight) at external sulfate concentrations $\left(\left[\mathrm{SO}_{4}{ }^{2-}\right]_{\text {crit }}\right)$ of about 26 or $21 \mu \mathrm{M}$, for shoots or roots, respectively. The inhibitory effect of $\mathrm{Cd}$ on plant growth was concentrationdependent, as indicated by the comparison of the plants grown under the same sulfate concentration. On the other hand, the effect of each Cd concentration on shoot or root fresh weight was independent of the sulfate concentration, as indicated by the 

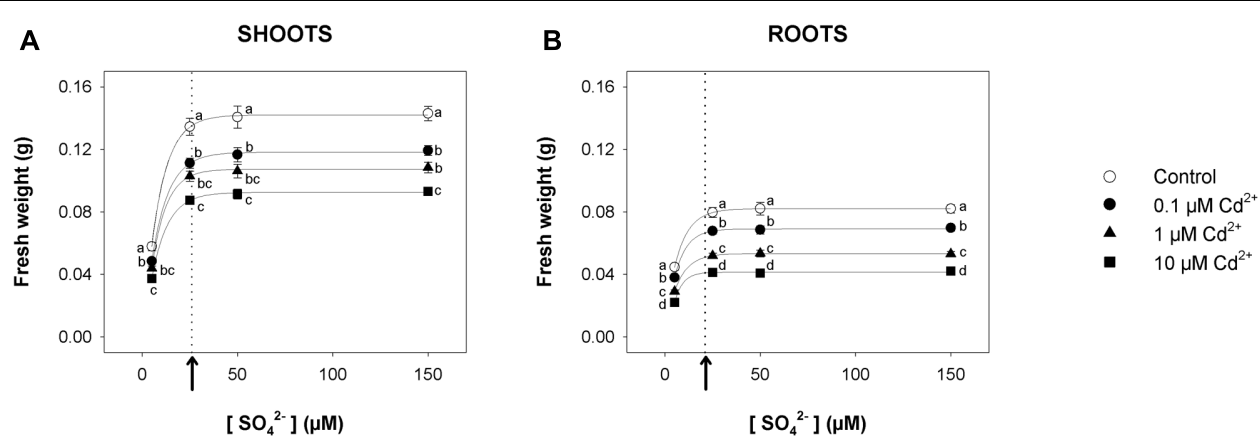

FIGURE 1 | Effect of short-term exposure to $\mathbf{C d}$ on shoot and root growth as a function of the sulfate concentration in the external medium. Arabidopsis plants were pre-grown for 19 days under four sulfate concentrations $(5,25,50$, and $150 \mu \mathrm{M})$ and then exposed for $72 \mathrm{~h}$ to three concentrations of $\mathrm{Cd}^{2+}(0.1,1$, and $10 \mu \mathrm{M})$. The characteristic curves describing shoot and root fresh weight accumulation in relation to the external sulfate were drawn by fitting a three-parameter exponential rise to maximum function to the data obtained by weighing the shoot and the roots of the Arabidopsis plants at the end of each experiment. (A) Shoot fresh weight accumulation. The correlation coefficients of the fittings were: 0.999 for the control, and 0.999, 0.999, 0.999 for plants exposed to $0.1,1,10 \mu \mathrm{M} \mathrm{Cd}^{2+}$, respectively. (B) Root fresh weight accumulation. The correlation coefficients of the fittings were: 0.999 for the control, and 0.998, 0.999 , 0.996 for plants exposed to $0.1,1,10 \mu \mathrm{M} \mathrm{Cd}^{2+}$, respectively. Data are means and SE of two experiments run in triplicate $(n=6)$. Different letters indicate significant differences $(P<0.05)$. Dotted lines and arrows indicate $\left[\mathrm{SO}_{4}{ }^{2-}\right]_{\text {crit }}$.

analyses of the growth normalized with respect to the control (i.e., relative growth; Supplementary Figure S1).

Short-term exposure to Cd significantly changed the NPT levels of both shoots and roots, which increased as Cd concentration did under all the sulfate concentrations analyzed (Figures 2A,B). Such trends were mainly related to the accumulation of non-GSH NPTs (mainly PCs and related peptides), which became the most abundant class of thiols in the tissues of Cd-exposed plants (Figures 2E,F). Opposite behaviors were observed as regards the effects of $\mathrm{Cd}$ on the total GSH levels of shoots and roots. In fact, for each sulfate concentration, the levels of total GSH significantly increased or decreased, considering shoots or roots, respectively, as the $\mathrm{Cd}$ concentration in the growing medium increased (Figures 2C,D). Moreover, for each $\mathrm{Cd}$ concentration, the dependence of the NPT, total GSH, and non-GSH NPT levels on the external sulfate was described by typical exponential rise to maximum curves, approaching the saturation at sulfate concentrations very close to the critical ones. Finally, $\mathrm{Cd}$ concentration was higher in the roots than in the shoots; its concentration in the shoot or root tissues was dependent on the level of the metal in the growing medium, but was unaffected by the sulfate concentration (Figures 2G,H).

The capacity of the Arabidopsis roots to take up sulfate was strongly affected by the sulfate availability in the growing medium, as well as by the presence of $\mathrm{Cd}$, as indicated by the values of ${ }^{35} \mathrm{~S}$-sulfate uptake measured at $150 \mu \mathrm{M} \mathrm{SO}_{4}{ }^{2-}$ external concentration (Figure 3A). In the control plants, the rate of sulfate uptake increased up to 1.2-fold, moving the external sulfate concentration from 150 to $5 \mu \mathrm{M}$. A Cd-dependent increase in the rate of sulfate uptake was also observed in the Arabidopsis plants grown under the same sulfate concentration in the media. Sulfate uptake increases of 1.7-, 2.0-, 2.2-, and 1.6fold were measured in plants grown under 5, 25, 50, and $150 \mu \mathrm{M}$ external sulfate, respectively, moving the $\mathrm{Cd}^{2+}$ concentration from 0 to $10 \mu \mathrm{M}$. These behaviors were closely associated to changes in the relative transcript levels of SULTR1; 1 (Figure 3B) and SULTR1; 2 (Figure 3C), the two Arabidopsis genes involved in sulfate uptake by roots (Maruyama-Nakashita et al., 2004).

\section{Effect of Long-Term Exposures to Cd under Different Sulfate Concentrations on Growth, Thiol Content, Cd Accumulation, and Sulfate Uptake of Arabidopsis Plants}

For long-term exposure experiments, we grew Arabidopsis plants for 22 days under a wide range of sulfate concentrations $(1,2.5$, $5,7.5,10,25,50,75,100,125$, and $150 \mu \mathrm{M} \mathrm{MgSO} 4)$, in the presence or absence of $0.1 \mu \mathrm{M} \mathrm{CdCl}$. As previously shown, the data set distribution of shoot and root fresh weights (obtained in each treatment condition) as a function of the external sulfate concentration was properly described by an exponential rise to maximum function, which allowed us to calculate the relative $\left[\mathrm{SO}_{4}{ }^{2-}\right]_{\text {crit }}$ maximizing the growth in each experimental condition. Such a value, calculated for the shoots (Figure 4A), was significantly higher in Cd-treated $(40.9 \pm 1.2 \mu \mathrm{M})$ than in control plants $(28.8 \pm 0.6 \mu \mathrm{M})$, whilst, for the roots (Figure $4 \mathbf{B}$ ), was independent of the presence of Cd $(19.4 \pm 0.3 \mu \mathrm{M}$ and $18.3 \pm 0.5 \mu \mathrm{M}$, for control and Cd-treated plants, respectively). Interestingly, the analysis of the growth curves also revealed that $\mathrm{Cd}$ exposure exerted inhibitory effects on shoot growth only at sulfate concentrations lower than $\left[\mathrm{SO}_{4}{ }^{2-}\right]_{\text {crit }}$. At sulfate external concentrations higher than $\left[\mathrm{SO}_{4}{ }^{2-}\right]_{\text {crit }}$ the presence of $\mathrm{Cd}$ did not affect shoot growth (Figure 4A). Moreover, the effects produced by $\mathrm{Cd}$ on shoot growth were closely dependent on the sulfate concentration, since they reduced as the sulfate concentration in the medium increased up to the value of $\left[\mathrm{SO}_{4}{ }^{2-}\right]_{\text {crit }}$ (Supplementary Figure S2A). Conversely, the effects of $\mathrm{Cd}$ on root growth were independent of the sulfate concentration in the growing medium (Supplementary Figure S2B). 


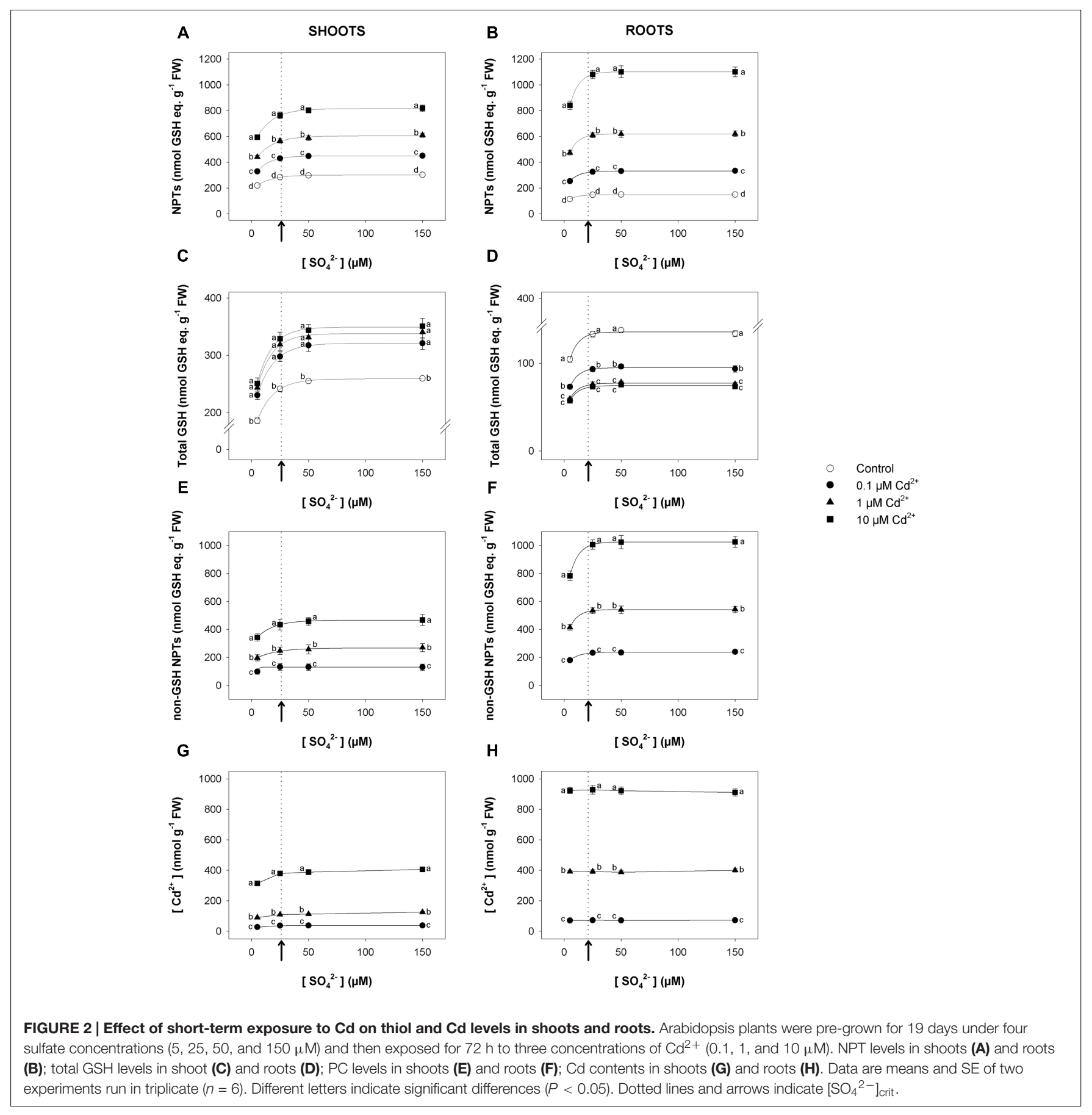

The relationship between the NPT level and the sulfate concentration in the medium exhibited a saturation behavior for both shoots and roots (Figures 5A,B). In particular, the NPT levels measured in the shoots were significantly higher in Cdexposed than in control plants at sulfate external concentrations higher than $\left[\mathrm{SO}_{4}{ }^{2-}\right]_{\text {crit; }}$ no significant effects were observed at sulfate concentrations lower than $\left[\mathrm{SO}_{4}{ }^{2-}\right]_{\text {crit }}$ (Figure 5A). On the other hand, the NPT levels in the Cd-exposed roots were significantly higher than in the control under all the sulfate concentrations analyzed (Figure 5B). Such behaviors were associated with notable changes in the balance among the different classes of thiols, whose relative abundance seemed to be dependent on: (i) the presence/absence of $\mathrm{Cd}$ in the growing medium; (ii) the sulfate external concentration; (iii) the plant tissues we considered. The analyses of the curves describing the dependence of the total GSH levels of the shoots on the sulfate external concentration revealed that the inhibitory effects exerted by $\mathrm{Cd}$ on the GSH accumulation gradually decreased, moving the external sulfate concentration up to the critical value calculated for this condition. At sulfate external concentrations 


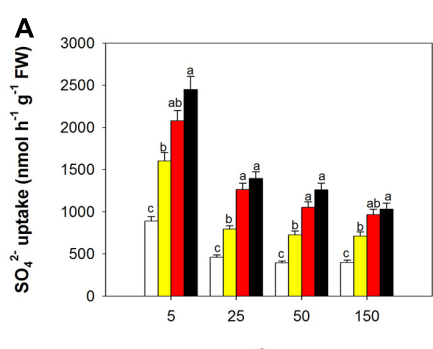

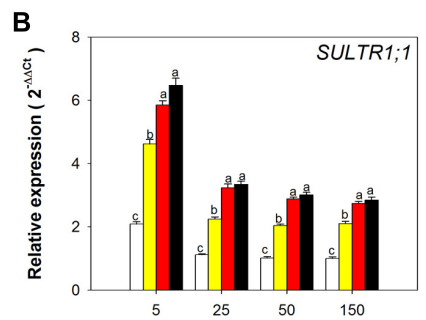

$\left[\mathrm{SO}_{4}^{2-}\right](\mu \mathrm{M})$

$\left[\mathrm{SO}_{4}{ }^{2-}\right](\mu \mathrm{M})$

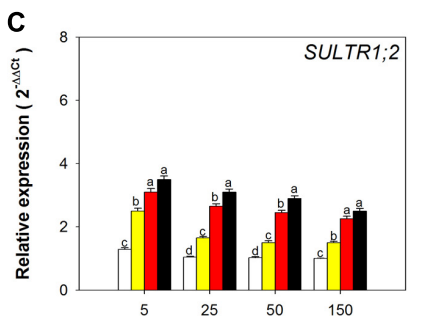

$\left[\mathrm{SO}_{4}{ }^{2-}\right](\mu \mathrm{M})$

$$
\begin{array}{ll}
\square & \text { Control } \\
\square & 0.1 \mu \mathrm{M} \mathrm{Cd}^{2+} \\
& 1 \mu \mathrm{M} \mathrm{Cd}^{2+} \\
& 10 \mu \mathrm{Mdd}^{2+}
\end{array}
$$

FIGURE 3 | Effect of short-term exposure to Cd on the sulfate uptake capacity of the roots. Arabidopsis plants were pre-grown for 19 days under four sulfate concentrations $(5,25,50$, and $150 \mu \mathrm{M})$ and then exposed for $72 \mathrm{~h}$ to three concentrations of $\mathrm{Cd}^{2+}(0.1$, 1 , and $10 \mu \mathrm{M})$. (A) Sulfate uptake capacity was evaluated by measuring the rate of ${ }^{35} \mathrm{SO}_{4}{ }^{2-}$ absorption into roots of intact plants over a 15 min pulse. The incubation solutions contained 150 $\mu \mathrm{M} \mathrm{SO}{ }_{4}{ }^{2-}$. (B,C) Changes in the relative transcript levels of SULTR1; 1 and SULTR1; 2 in the roots. Bars and error bars are means and SE of two experiments run in triplicate ( $n=6)$. Different letters indicate significant differences $(P<0.05)$.
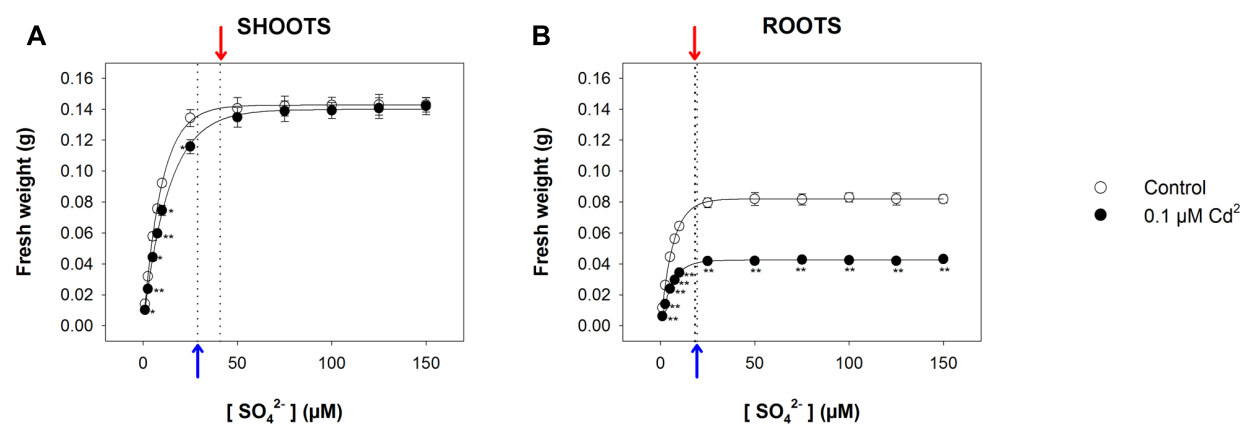

FIGURE 4 | Effect of long-term exposure to $\mathbf{C d}$ on shoot and root growth as a function of the sulfate concentration in the external medium. Arabidopsis plants were grown for 22 days under a wide range of sulfate concentrations $(1,2.5,5,7.5,10,25,50,75,100,125$, and $150 \mu \mathrm{M})$ in the presence or absence of $0.1 \mu \mathrm{M} \mathrm{Cd}^{2}+$. The characteristic curves describing shoot and root fresh weight accumulation in relation to the external sulfate were drawn by fitting a three-parameter exponential rise to maximum function to the data obtained by weighing the shoot and the roots of the Arabidopsis plants at the end of each experiment. (A) Shoot fresh weight accumulation. The correlation coefficients of the fittings were 0.999 and 0.999 , for control and Cd-exposed plants, respectively. (B) Root fresh weight accumulation. The correlation coefficients of the fittings were 0.999 and 0.999, for control and Cd-exposed plants, respectively. Data are means and SE of two experiments run in triplicate $(n=6)$. Asterisks indicate significant differences (Student's $t$-test; $\left.{ }^{*} 0.001 \leq P<0.05 ; * * P<0.001\right)$ between

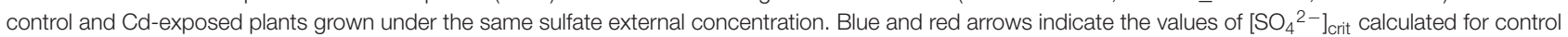
and Cd-exposed plants, respectively.

higher than $\left[\mathrm{SO}_{4}{ }^{2-}\right]_{\text {crit }}$ the presence of $\mathrm{Cd}$ did not affect the total GSH levels, whose values were similar to those measured in the control (Figure 5C). Such behavior was closely related to the levels of the non-GSH NPT in the shoot tissues, which progressively decreased as the sulfate concentration increased, up to a constant value at sulfate concentrations higher than $\left[\mathrm{SO}_{4}{ }^{2-}\right]_{\text {crit }}$ (Figure 5E). A different picture was evinced by analyzing the dependence of total GSH and non-GSH NPT levels of the roots on the external sulfate concentration. Interestingly, in Cd-exposed roots the total GSH levels were significantly higher than in the control and did not show any apparent dependence on the sulfate external concentration (Figure 5D), differently from the non-GSH NPT levels, whose dependence on the sulfate external concentration was properly described by a saturation curve (Figure 5F). Finally, it is worth noting that the concentration of $\mathrm{Cd}$ in both shoots and roots was not constant under all the sulfate concentration analyzed, showing a dependence on sulfate external concentration similar to that described for the concentrations of the non-GSH NPTs in each apparatus (Figures 5G,H).

Since reduced GSH not only represents the key intermediate for the synthesis of PCs, but also plays a pivotal role as an antioxidant in controlling the cellular redox status, we measured the GSH/GSSG ratio in all the experimental conditions, assuming this value as a marker for oxidative stress. Results (Figure 6 and Supplementary Figure S3) revealed that in this case also, the relationship between the GSH/GSSG ratio measured in both shoots and roots and the sulfate concentration in the medium was described, in each condition, by a saturation curve, indicating that the optimal cellular redox status was reached at sulfate concentrations higher than the respective critical values. In particular, the GSH/GSSG ratio measured in the 


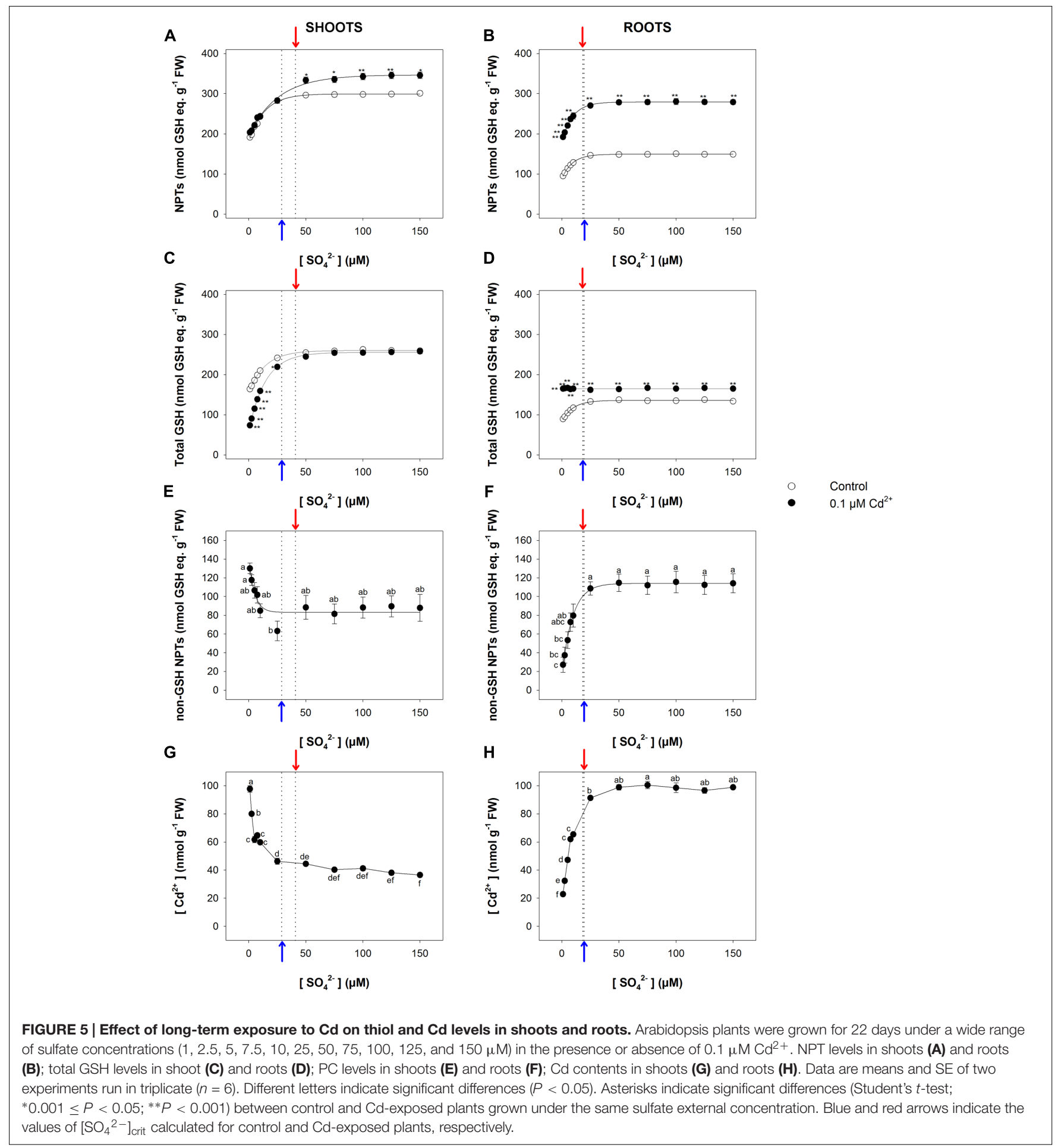

shoots was significantly lower in Cd-exposed than in control plants at sulfate external concentrations lower than $\left[\mathrm{SO}_{4}{ }^{2-}\right]_{\text {crit }}$; no significant effects were observed at sulfate concentrations higher than $\left[\mathrm{SO}_{4}{ }^{2-}\right]_{\text {crit }}$ (Figure 6A). Conversely, the GSH/GSSG ratio in the Cd-exposed roots were significantly lower than in the control under all the sulfate concentrations analyzed (Figure 6B).
Finally, the rate of sulfate uptake - measured at $150 \mu \mathrm{M}$ $\mathrm{SO}_{4}{ }^{2-}$ external concentration at the end of the exposure period increased as the sulfate concentration in the growing medium decreased, but was significantly higher in Cd-exposed than in control plants under all the sulfate concentrations analyzed (Figure 7A). Close relationships between the rate of sulfate uptake and the relative transcript levels of SULTR1; 1 (Figure 7B) 

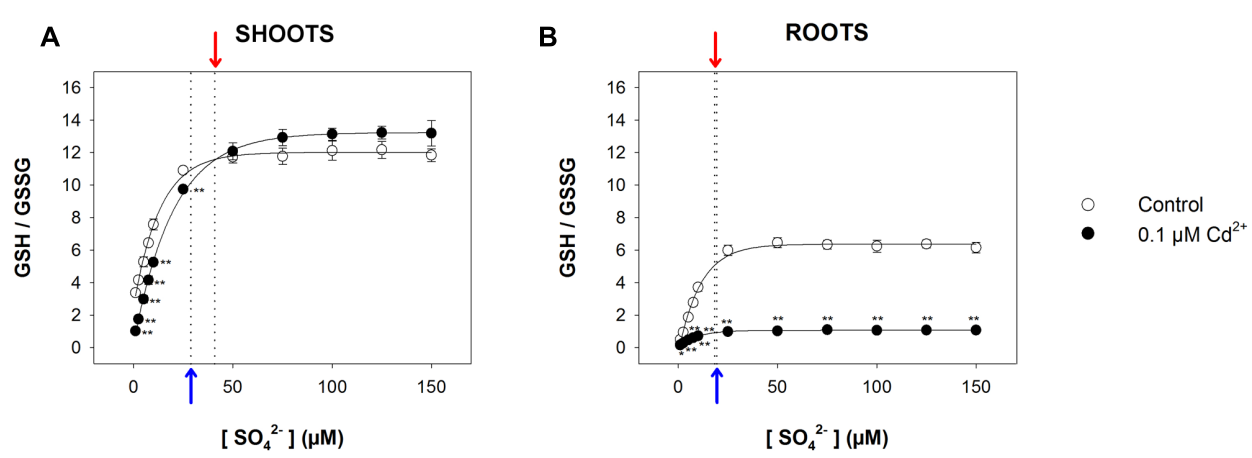

FIGURE 6 | Effect of long-term exposure to Cd on the GSH/GSSG ratio in shoots (A) and roots (B). Arabidopsis plants were grown for 22 days under a wide range of sulfate concentrations $(1,2.5,5,7.5,10,25,50,75,100,125$, and $150 \mu \mathrm{M})$ in the presence or absence of $0.1 \mu \mathrm{M}$ Cd $2+$. The GSH/GSSG ratios were calculated using data about reduced GSH and GSSG reported in Supplementary Figure S3. Data are means and SE of two experiments run in triplicate ( $n=6$ ). Asterisks indicate significant differences (Student's $t$-test; ${ }^{*} 0.001 \leq P<0.05$; ${ }^{* *} P<0.001$ ) between control and Cd-exposed plants grown under the same sulfate external concentration. Blue and red arrows indicate the values of $\left[\mathrm{SO}_{4}{ }^{2-}\right]_{\text {crit }}$ calculated for control and Cd-exposed plants, respectively.

and SULTR1; 2 (Figure 7C) were also observed in this set of experiments.

\section{DISCUSSION}

Several papers report that early $\mathrm{Cd}$ stress triggers a wide range of adaptive mechanisms - involving GSH consuming activities which may increase the metabolic demand for sulfate, sulfur metabolites and carbon skeletons (Lee and Leustek, 1999; Nocito et al., 2006, 2008). In fact GSH not only is polymerized to form PCs in response to Cd accumulation (Xiang et al., 2001; Rea et al., 2004), but also acts as an antioxidant in mitigating the oxidative stress produced by free $\mathrm{Cd}^{2+}$ ions into the cells (Cuypers et al., 2011; Noctor et al., 2012). In such a context, the need to maintain GSH homeostasis and continuous Cd chelation induces responses allowing plants to increase sulfate uptake by roots and sulfate entry in the reductive assimilation pathway, as well as to modulate sulfate allocation among the different tissues and organs. Such responses are mainly controlled at transcriptional level and involve transcript accumulation of genes that encode sulfate transporters and activities along the pathways of sulfate assimilation and GSH biosynthesis (Lee and Leustek, 1999; Nocito et al., 2002, 2006; Lancilli et al., 2014; Yamaguchi et al., 2016). The pivotal importance of sulfate uptake in the plant adaptation to $\mathrm{Cd}$ stress has recently been underlined by the analysis of the Arabidopsis sultr1; 1-sultr1; 2 double mutant - defective in two distinct high-affinity sulfate transporters (SULTR1; 1 and SULTR1; 2) involved in root sulfate uptake from the rhizosphere - which resulted, under limited sulfate supply, in plants being more sensitive to Cd-induced oxidative stress than the wild type (Liu et al., 2016). Moreover, analyses of Arabidopsis mutants defective in thiol metabolism and accumulation revealed that

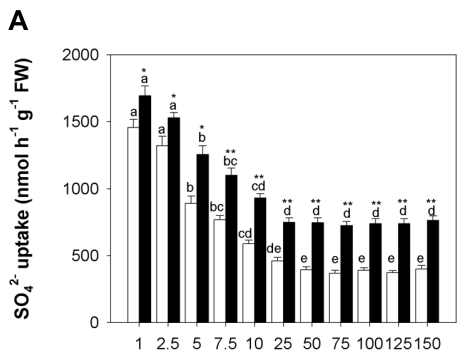

[ $\mathrm{SO}_{4}^{2-}$ ] ( $\left.\mu \mathrm{M}\right)$

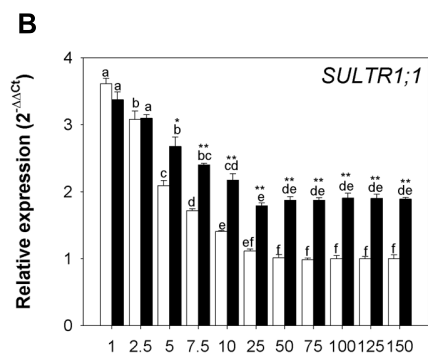

[ $\left.\mathrm{SO}_{4}{ }^{2-}\right]$ ( $\left.\mu \mathrm{M}\right)$

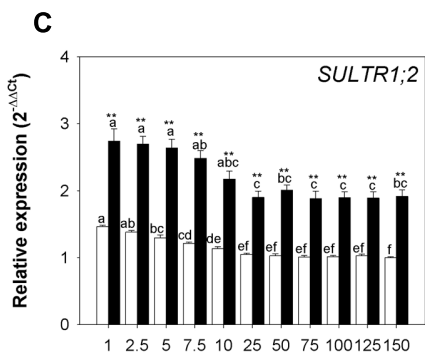

[ $\left.\mathrm{SO}_{4}{ }^{2-}\right]$ ( $\left.\mu \mathrm{M}\right)$ 
both oxidative stress and thiol depletion are necessary to induce the transcription of SULTR1; 2 during early Cd stress (Jobe et al., 2012). Thus, while the contribution of Cdinduced sulfate uptake to the early phases of Cd-detoxification appears evident, the role of sulfate uptake and $S$ nutrition in maintaining plant growth under prolonged $\mathrm{Cd}$ exposure still needs to be elucidated, since long-term exposure to $\mathrm{Cd}$ may permanently affect thiol homeostasis and allocation to different sinks, ultimately affecting the plant's capacity to optimize its growth at a given sulfate concentration in the external medium.

The analyses of the dependence of both shoots and root fresh weight on the amount of external sulfate available for growth (Figures 1, 4) may allow some educated guesses on how plants optimize growth at a given sulfate concentration. For this reason we calculated for each condition the $\left[\mathrm{SO}_{4}{ }^{2-}\right]_{\text {crit }}$ (i.e., the sulfate concentration in the growing medium that produced $95 \%$ of the maximum amount of fresh weight for shoots or roots), assuming that changes in this value necessarily reflect changes in the plant's ability to use the external S sources to promote growth.

Starting from the deficiency range, increasing the sulfate supply increases plant growth although the response diminishes as the supply of sulfate ions is increased according to the low of diminishing yield increment formulated by McNall (1933), Mitscherlich (1954), and Engels et al. (2012). In the second part of the curves (i.e., at sulfate concentration higher than $\left[\mathrm{SO}_{4}{ }^{2-}\right]_{\text {crit }}$ ) increasing of the sulfate supply does not produce any significant growth increment, indicating that other nutrients, environmental factors or the "genetic potential" of the plant become limiting factors.

Data analysis reveals that short-term exposure to Cd negatively affects plant growth but does not produce any significant effects on the growth pattern of shoots or roots in relation to the external sulfate, as indicated by the invariance of the $\left[\mathrm{SO}_{4}{ }^{2-}\right]_{\text {crit }}$ determined for shoot or root growth under each experimental condition (Figure 1 and Supplementary Figure S1). On the other hand, long-term exposure to $\mathrm{Cd}$ significantly changes the pattern of fresh weight accumulation of the shoots in relation to the external sulfate, and significantly enhances the $\left[\mathrm{SO}_{4}{ }^{2-}\right]_{\text {crit }}$ maximizing the growth (Figure 4A). It is also worth noting that in this condition, increasing the sulfate external concentration up to the $\left[\mathrm{SO}_{4}{ }^{2-}\right]_{\text {crit }}$ progressively reduces the inhibitory effects exerted by the same concentration of Cd on shoot growth (Supplementary Figure S2A), indicating that - at least in our conditions - plant tolerance to relatively low $\mathrm{Cd}$ concentrations is dependent to the $\mathrm{S}$ nutritional status, as previously observed in maize seedlings grown under different sulfate availabilities (Nocito et al., 2006). Such a behavior seems to be related to multiple and complex effects induced by the increase of the sulfate concentration in a range of sub-optimal availability for plant growth, which by affecting thiol biosynthesis produces serious effects on non-GSH NPT accumulation, Cd partitioning between shoots and roots, and cellular redox state (Figures 5, 6). In such a scenario, the increase in the non-GSH NPT levels of the roots (mainly PCs and related peptides) induced by enhancing sulfate (Figure 5F) progressively results in a greater capacity to retain $\mathrm{Cd}$ within the roots (Figure 5H), and thus reduces the amount of free $\mathrm{Cd}^{2+}$ ions that - escaping chelation - is potentially available to be translocated via the xylem in a root-to-shoot direction (Wong and Cobbett, 2009; Nocito et al., 2011). The analysis of changes in the shoot $\mathrm{Cd}$ concentration in relation to the external sulfate (Figure 5G) further supports this conclusion, underlining that the sulfate-induced enhancement in $\mathrm{Cd}$ root retention contributes to reduce $\mathrm{Cd}$ accumulation and injury in the shoot tissues (Figures 4A, 5G, and Supplementary Figure S2A). Moreover, the increase in the sulfate external concentration progressively reduces the negative effect of $\mathrm{Cd}$ on the level of reduced GSH in the shoots (Supplementary Figure S3A), enhancing the cellular capacity to cope with Cdinduced oxidative stress. Such an effect allows the shoot tissues to progressively contrast the oxidative damage exerted by $\mathrm{Cd}$, until reaching complete recovery at sulfate concentrations higher than $\left[\mathrm{SO}_{4}{ }^{2-}\right]_{\text {crit }}$, i.e., where the cells of the shoot tissues reached the optimal redox status, as indicated by the values of GSH/GSSG ratio that we assume as indicators of oxidative stress (Figure 6A). Conversely, the lack in the roots of a "sulfate-induced recovery" from Cd damage (Figure 4B and Supplementary Figure S2B) indicates that the increase in the total GSH levels of the roots induced by long-term exposure to $\mathrm{Cd}$ may be not enough to fully sustain $\mathrm{Cd}$ detoxification processes and thus to efficiently counteract the redox imbalance produced by $\mathrm{Cd}$ in the root tissues (Figures 5D, 6B).

Taken as a whole the behaviors discussed so far clearly suggest that the sulfate-dependent adaptive responses to longterm exposure to $\mathrm{Cd}$ may be part of the general physiological and biochemical mechanisms acting as a "firewall" to prevent excessive Cd accumulation in the shoot tissues (Mendoza-Cózatl et al., 2011). The efficiency of these responses seems to be related to the concentration of the sulfate ions in the growing medium, since the shoot recovery from Cd stress requires a higher sulfate concentration than that required to maximize shoot growth in the absence of Cd.

Data analysis also reveals that the induction of sulfate uptake is a common adaptive response to both short- and long-term exposure to Cd (Figures $\mathbf{3 A}, \mathbf{7 A}$ ). In fact, under all the sulfate concentrations analyzed, the presence of $\mathrm{Cd}$ in the growing medium modulates the well-known effects of the sulfate external concentration on the capacity of the Arabidopsis roots to take up sulfate (Takahashi et al., 1997; Shibagaki et al., 2002; Yoshimoto et al., 2002, 2007; Rouached et al., 2008). Such a modulation seems to be related to a differential regulation of the transcription of SULTR1; 1 and SULTR1; 2, the two Arabidopsis genes involved in sulfate uptake by roots (Figures 3B,C, 7B,C), probably as a consequence of the $\mathrm{Cd}$-induced changes in thiol metabolism and partitioning. However, a careful comparison of the amounts of the NPTs accumulated in each plant, in the presence or absence of $\mathrm{Cd}$, clearly reveals the existence of a differential and time-dependent effect of $\mathrm{Cd}$ exposure on thiol accumulation, and thus on the nutritional need for $\mathrm{S}$ generated by Cd (Supplementary Figure S4). In our experiments, shortterm exposure to $\mathrm{Cd}$ decreases the level of total $\mathrm{S}$ accumulated by a single plant (Supplementary Figure S4C) - probably in relation to the negative effect of the metal on shoot and root 
growth - and induces additional sinks for thiols whose strengths are closely dependent on the concentration of the metal in the growing medium (Supplementary Figure S4A), as previously reported by Lancilli et al. (2014). In such conditions, the increase in the relative expression of SULT1; 1 and SULTR1; 2 seems to be due to homeostatic mechanisms driven by the $\mathrm{Cd}$-induced increase in the total NPT levels per plant, since under all the sulfate concentrations analyzed, the presence of $0.1,1$, or $10 \mu \mathrm{M}$ $\mathrm{Cd}^{2+}$ positively affected both sulfate transporter gene expression and total NPT levels (Figures 8A,B). Conversely, long termexposure to $\mathrm{Cd}$ does not produce additional sinks for thiols and significantly reduces the level of total $S$ accumulated by each plant grown under sulfate external concentration lower than $\left[\mathrm{SO}_{4}{ }^{2-}\right]_{\text {crit }}$ (Supplementary Figures S4B,D). In this condition the total amount of NPTs per plant, calculated for each sulfate concentration, was not significantly affected by the presence of $0.1 \mu \mathrm{M} \mathrm{Cd}^{2+}$ (Supplementary Figure S4B), and the relationship between changes in the relative expression of SULTR1; 1 or SULTR1; 2 transcript and the total amount of NPTs per plant appears to be more complex than those described under shortterm exposure to $\mathrm{Cd}$ (Figures 9A,B). Considering the plots in Figures 9A,B we can easily evince that, under the same sulfate concentration, the $\mathrm{Cd}$-induced increase in transcript level of SULTR1; 1 or SULTR1; 2 does not produce any significant changes in the total amount of NPTs per plant. Such a finding indicates that long-term exposure to $\mathrm{Cd}$, even if results in a greater rate of sulfate uptake (Figure 7A), negatively affects the capacity of the entire root apparatus to absorb the external sulfate at concentration lower than $\left[\mathrm{SO}_{4}{ }^{2-}\right]_{\text {crit }}$, probably because of the dramatic effect produced by $\mathrm{Cd}$ on the pattern of fresh weight accumulation of the roots (Figure 4B). Such a behavior clearly indicates that the interaction between the molecular mechanisms controlling sulfate uptake and root development under different sulfate concentrations may limit the capacity of the root apparatus to optimize the external sulfate supply under long-term exposure to $\mathrm{Cd}$. The capacity of the roots to adequate sulfate fluxes and sulfate transporter gene expression in the sulfate deficiency range (Figure 7) indicates that below the $\left[\mathrm{SO}_{4}{ }^{2-}\right]_{\text {crit }}-$ calculated for the shoots of the control plants both sulfate supply and relative expressions of SULTR1; 1 and SULTR1; 2 limit the Arabidopsis growth potential in our environmental conditions (i.e., light, photoperiod, temperature, nutrient availability, etc.). The presence of $\mathrm{Cd}$ in the growing medium significantly alters thiol metabolism and partitioning, promotes sulfate uptake and increases the $\left[\mathrm{SO}_{4}{ }^{2-}\right]_{\text {crit }}$, but does not change the range of sulfate external concentrations in which sulfate uptake appears to be modulated (e.g., from 1 to $25 \mu \mathrm{M}$ ), suggesting that sulfate perception in the growing medium may play an important role in this response. Recent advances in our knowledge of the mechanisms controlling sulfate

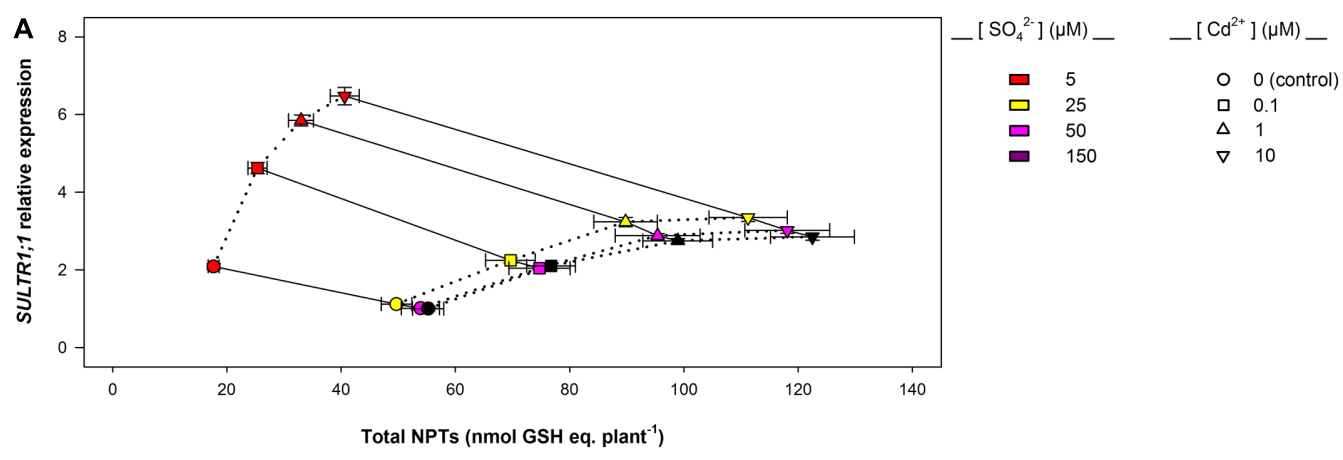

B

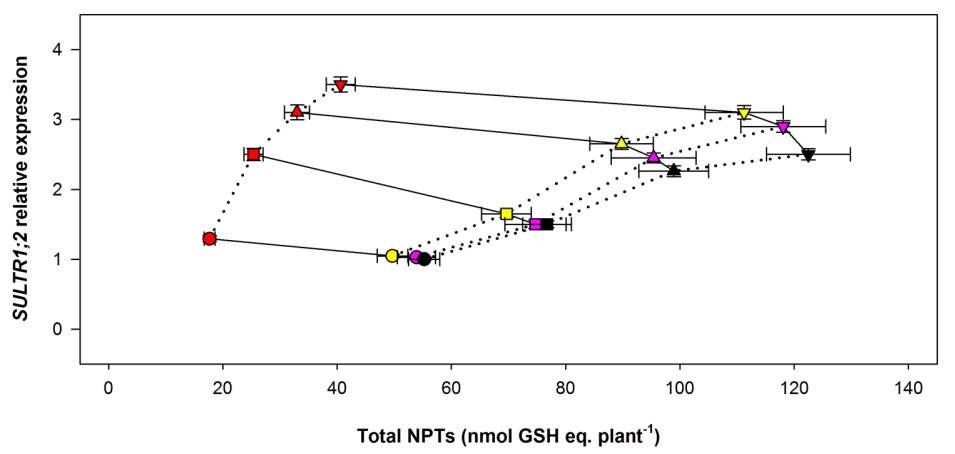

FIGURE 8| SULTR1; 1 (A) and SULTR1; 2 (B) relative expression vs. total NPT levels per plant: short-term exposure. The relationships between the relative expression of SULTR1; 1 or SULTR1; 2 transcript and the total amount of NPTs per plant were evinced using data reported in Figure $\mathbf{3}$ and Supplementary Figure S4. Solid lines link data about plants exposed to the same Cd concentration (circles, $0 \mu \mathrm{M} \mathrm{Cd}^{2+}$; squares, $0.1 \mu \mathrm{M} \mathrm{Cd}{ }^{2+}$; triangles up, $1 \mu \mathrm{M} \mathrm{Cd}{ }^{2+}$; triangles down, $10 \mu \mathrm{M} \mathrm{Cd}^{2+}$ ), under different sulfate availabilities. Dotted lines link data about plants grown under the same sulfate concentration in the absence or presence of different $\mathrm{Cd}^{2+}$ concentrations. Data reported in each plot are means and SE of two experiments run in triplicate $(n=6)$. 


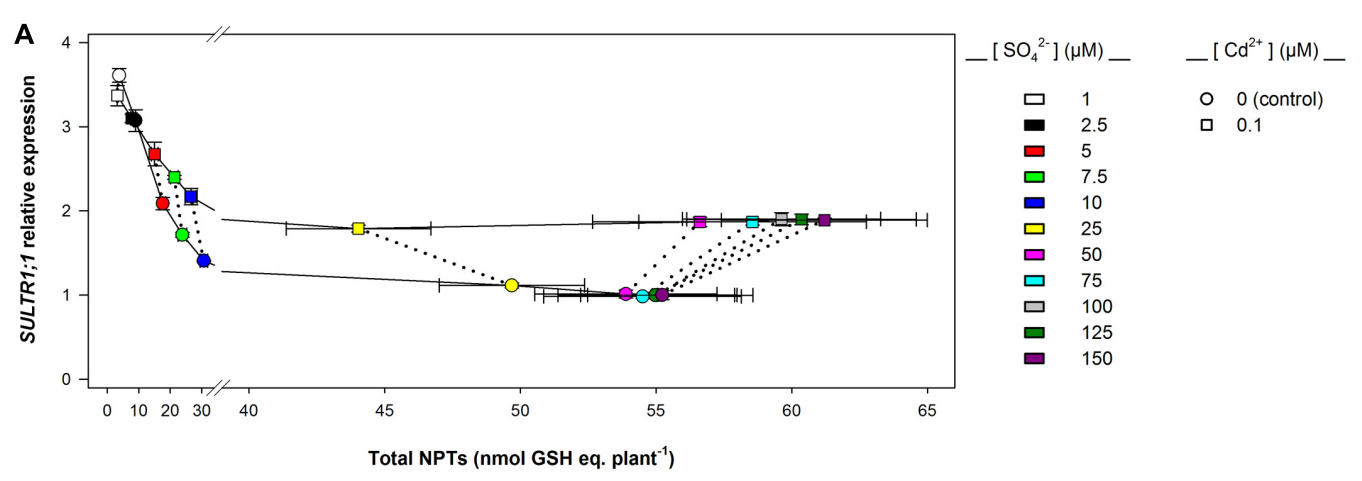

B

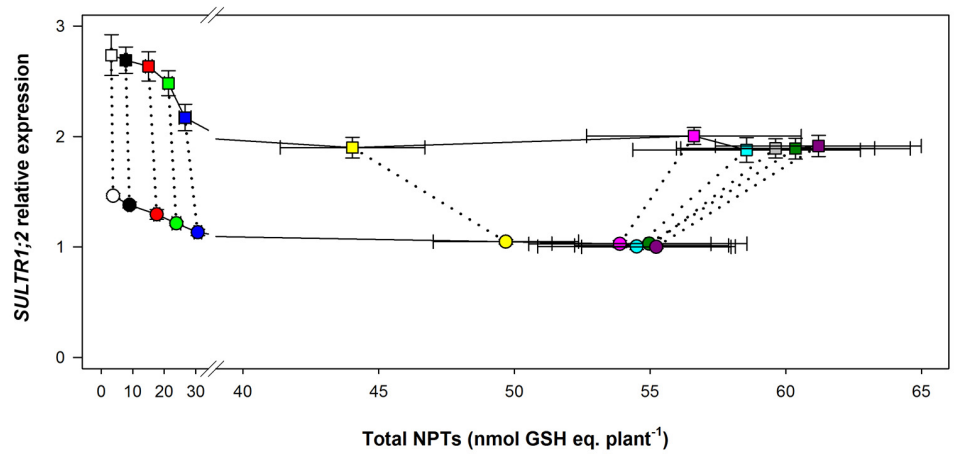

FIGURE 9 | SULTR1; 1 (A) and SULTR1; 2 (B) relative expression vs. total NPT levels per plant: long-term exposure. The relationships between the relative expression of SULTR1; 1 or SULTR1; 2 transcript and the total amount of NPTs per plant were evinced using data reported in Figure 7 and Supplementary Figure S4. Solid lines link data about plants grown under different sulfate concentrations in the absence (circles) or presence of $0.1 \mu \mathrm{M} \mathrm{Cd^{2+ }}(\mathrm{squares})$. Dotted lines link data about plants grown under the same sulfate concentration. Data reported in each plot are means and SE of two experiments run in triplicate $(n=6)$.

uptake and assimilation point out that these pathways are not only regulated by the demand for reduced sulfur, but also by phytohormones and various environmental factors, such as extracellular sulfate availability (Koprivova and Kopriva, 2014; Zheng et al., 2014). Physiological evidences have shown that the sulfate transporter SULTR1; 2 of Arabidopsis may has an additional role in the extracellular $S$ sensing that could be independent of the perception of the internal $S$ status or nutritional request, since mutations in the relative gene reduce sensitivity to the S-transcriptional repression of key S-responsive genes (Zhang et al., 2014). In this context, sensing of extracellular sulfate may limit further sulfate uptake under long-term exposure to $\mathrm{Cd}$, even if the metabolic demand for reduced sulfur is high, and thus reduces the capacity of the plants to optimize sulfate uptake in relation to root growth. In fact, under long term-exposure to $\mathrm{Cd}$ the relative growth of the roots was only about $52.5 \%$ with respect to the control, under all the sulfate concentrations analyzed, whilst the -fold change for the potential capacity of the roots to take up sulfate (measured at saturation) ranged from 0.2 to 1 , moving the sulfate external concentration from 1 to $150 \mu \mathrm{M}$. From these data we can calculate that Cd-exposed plants became able to absorb the same amount of sulfate as control plants at $56.9 \mu \mathrm{M}$ external $\mathrm{SO}_{4}{ }^{2-}$, i.e., where the -fold change for the potential capacity of the roots to take-up sulfate reached the value of 0.9 (Supplementary Figure S5). In these conditions $\left(\left[\mathrm{SO}_{4}{ }^{2-}\right]_{\text {out }} \geq 56.9 \mu \mathrm{M}\right)$, the induction of sulfate uptake is potentially able to balance the negative effects of $\mathrm{Cd}$ on root growth and then to assure an adequate sulfate amount for optimizing shoot growth and thiol metabolism.

\section{CONCLUSION}

Our results indicate that long term-exposure to $\mathrm{Cd}$, although it induces sulfate uptake, decreases the capacity of the Arabidopsis roots to efficiently absorb the sulfate ions available in the growing medium to promote growth. Such a behavior is likely due to an effect exerted by $\mathrm{Cd}$ accumulation which - by reducing the development of the root apparatus - makes the adaptive response of the high-affinity sulfate transporters "per se" not enough to optimize the growth at sulfate external concentrations lower than $\left[\mathrm{SO}_{4}{ }^{2-}\right]_{\text {crit }}$.

\section{AUTHOR CONTRIBUTIONS}

FN, CL, and GAS conceived and designed the experiments. AF, $\mathrm{MM}$, and FN performed the experiments and analyzed the data. GL performed the ICP-MS analysis. GAS acquired the funds. FN and AF wrote the manuscript. All authors discussed, revised, and approved the manuscript. 


\section{ACKNOWLEDGMENTS}

The music of Gustav Mahler's IX Symphony inspired this work. We would like to thank Prof Maurizio Cocucci for its precious support during the revision of the manuscript.

\section{REFERENCES}

Brunetti, P., Zanella, L., De Paolis, A., Di Litta, D., Cecchetti, V., Falasca, G., et al. (2015). Cadmium-inducible expression of the ABC-type transporter AtABCC3 increases phytochelatin-mediated cadmium tolerance in Arabidopsis. J. Exp. Bot. 66, 3815-3829. doi: 10.1093/jxb/erv185

Chen, A., Komives, E. A., and Schroeder, J. I. (2006). An improved grafting technique for mature Arabidopsis plants demonstrates long-distance shoot-toroot transport of phytochelatins in Arabidopsis. Plant Physiol. 141, 108-120 doi: 10.1104/pp.105.072637

Clemens, S. (2001). Molecular mechanisms of plant metal tolerance and homeostasis. Planta 212, 475-486. doi: 10.1007/s004250000458

Clemens, S. (2006). Toxic metal accumulation, responses to exposure and mechanisms of tolerance in plants. Biochimie 88, 1707-1719. doi: 10.1016/j. biochi.2006.07.003

Cobbett, C., and Goldsbrough, P. (2002). Phytochelatins and metallothioneins: roles in heavy metal detoxification and homeostasis. Annu. Rev. Plant Biol. 53 159-182. doi: 10.1146/annurev.arplant.53.100301.135154

Cobbett, C. S. (2000). Phytochelatins and their roles in heavy metal detoxification. Plant Physiol. 123, 825-832. doi: 10.1104/pp.123.3.825

Cuypers, A., Smeets, K., Ruytinx, J., Opdenakker, K., Keunen, E., Remans, T., et al. (2011). The cellular redox state as a modulator in cadmium and copper responses in Arabidopsis thaliana seedlings. J. Plant Physiol. 168, 309-316. doi: 10.1016/j.jplph.2010.07.010

Engels, C., Kirkby, E., and White, P. (2012). "Mineral nutrition, yield and sourcesink relationships," in Marschner's Mineral Nutrition of Higher Plants, ed. P. Marschner (London: Academic Press), 85-133. doi: 10.1016/B978-0-12384905-2.00005-4

Ernst, W. H., Krauss, G. J., Verkleij, J. A., and Wesenberg, D. (2008). Interaction of heavy metals with the sulphur metabolism in angiosperms from an ecological point of view. Plant Cell Environ. 31, 123-143.

Fontanili, L., Lancilli, C., Suzui, N., Dendena, B., Yin, Y.-G., Ferri, A., et al. (2016). Kinetic analysis of zinc/cadmium reciprocal competitions suggests a possible $\mathrm{Zn}$-insensitive pathway for root-to-shoot cadmium translocation in rice. Rice 4 16. doi: 10.1186/s12284-016-0088-3

Griffith, O. W. (1980). Determination of glutathione and glutathione disulfide using glutathione reductase and 2-vinylpyridine. Anal. Biochem. 106, 207-212. doi: 10.1016/0003-2697(80)90139-6

Grill, E., Winnacker, E.-L., and Zenk, M. H. (1987). Phytochelatins, a class of heavy-metal-binding peptides from plants, are functionally analogous to metallothioneins. Proc. Natl. Acad. Sci. U.S.A. 84, 439-443. doi: 10.1073/pnas. 84.2.439

Howden, R., Anderson, C. R., Goldsbrough, P. B., and Cobbett, C. S. (1995a) A cadmium-sensitive, glutathione-deficient mutant of Arabidopsis thaliana. Plant Physiol. 107, 1067-1073. doi: 10.1104/pp.107.4.1067

Howden, R., Goldsbrough, P. B., Anderson, C. R., and Cobbett, C. S. (1995b) Cadmium-sensitive, cadl mutants of Arabidopsis thaliana are phytochelatin deficient. Plant Physiol. 107, 1059-1066. doi: 10.1104/pp.107.4.1059

Jobe, T. O., Sung, D.-Y., Akmakjian, G., Pham, A., Komives, E. A., MendozaCózatl, D. G., et al. (2012). Feedback inhibition by thiols outranks glutathione depletion: a luciferase-based screen reveals glutathione-deficient $\gamma$-ECS and glutathione synthetase mutants impaired in cadmium-induced sulfate assimilation. Plant J. 70, 783-795. doi: 10.1111/j.1365-313X.2012. 04924.x

Jozefczak, M., Keunen, E., Schat, H., Bliek, M., Hernández, L. H., Carleer, R., et al. (2014). Differential response of Arabidopsis leaves and roots to cadmium glutathione-related chelating capacity vs antioxidant capacity. Plant Physiol. Biochem. 83, 1-9. doi: 10.1016/j.plaphy.2014.07.001

Khan, M. I. R., Iqbal, N., Masood, A., Mobin, M., Anjum, N. A., and Khan, N. A. (2016). Modulation and significance of nitrogen and sulfur metabolism in

\section{SUPPLEMENTARY MATERIAL}

The Supplementary Material for this article can be found online at: http://journal.frontiersin.org/article/10.3389/fpls.2017.00854/ full\#supplementary-material

cadmium challenged plants. Plant Growth Regul. 78, 1-11. doi: 10.1007/s10725 015-0071-9

Koprivova, A., and Kopriva, S. (2014). Molecular mechanisms of regulation of sulfate assimilation: first steps on a long road. Front. Plant Sci. 5:589. doi: 10.3389/fpls.2014.00589

Lancilli, C., Giacomini, B., Lucchini, G., Davidian, J.-C., Cocucci, M., Sacchi, G. A., et al. (2014). Cadmium exposure and sulfate limitation reveal differences in the transcriptional control of three sulfate transporter (SULTR1; 2) genes in Brassica juncea. BMC Plant Biol. 14:132. doi: 10.1186/1471-2229-14-132

Lee, S., and Leustek, T. (1999). The effect of cadmium on sulfate assimilation enzymes in Brassica juncea. Plant Sci. 141, 201-207. doi: 10.1016/S0168 9452(98)00231-3

Liu, X., Wu, F. H., Li, J. X., Chen, J., Wang, G. H., Wang, W. H., et al. (2016). Glutathione homeostasis and Cd tolerance in the Arabidopsis sultr1; 1-sultr1; 2 double mutant with limiting sulfate supply. Plant Cell Rep. 35, 397-413. doi: 10.1007/s00299-015-1892-8

Maruyama-Nakashita, A., Nakamura, Y., Yamaya, T., and Takahashi, H. (2004) Regulation of high-affinity sulphate transporters in plants: towards systematic analysis of sulphur signalling and regulation. J. Exp. Bot. 55, 1843-1849. doi: $10.1093 /$ jxb/erh175

McNall, P. E. (1933). The law of diminishing returns in agriculture. J. Agric. Res. 47, 167-178.

Mendoza-Cózatl, D. G., Jobe, T. O., Hauser, F., and Schroeder, J. I. (2011). Long-distance transport, vacuolar sequestration, tolerance, and transcriptional responses induced by cadmium and arsenic. Curr. Opin. Plant. Biol. 14 554-562. doi: 10.1016/j.pbi.2011.07.004

Mendoza-Cózatl, D. G., Loza-Tavera, H., Hernández-Navarro, A., and MorenoSánchez, R. (2005). Sulfur assimilation and glutathione metabolism under cadmium stress in yeast, protists and plants. FEMS Microbiol. Rev. 29, 653-671. doi: 10.1016/j.femsre.2004.09.004

Mendoza-Cózatl, D. G., Zhai, Z., Jobe, T. O., Akmakjian, G. Z., Song, W.-Y., Limbo, O., et al. (2010). Tonoplast-localized Abc2 transporter mediates phytochelatin accumulation in vacuoles and confers cadmium tolerance. J. Biol. Chem. 285, 40416-40426. doi: 10.1074/jbc.M110.155408

Mitscherlich, E. A. (1954). Bodenkunde fuer Landwirte, Foerster und Gaertner, 7th Edn. Berlin: Parey.

Nocito, F. F., Espen, L., Crema, B., Cocucci, M., and Sacchi, G. A. (2008). Cadmium induces acidosis in maize root cells. New Phytol. 179, 700-711. doi: 10.1111/ j.1469-8137.2008.02509.x

Nocito, F. F., Lancilli, C., Crema, B., Fourcroy, P., Davidian, J.-C., and Sacchi, G. A (2006). Heavy metal stress and sulfate uptake in maize (Zea mays L.) roots. Plant Physiol 141, 1138-1148. doi: 10.1104/pp.105.076240

Nocito, F. F., Lancilli, C., Dendena, B., Lucchini, G., and Sacchi, G. A. (2011). Cadmium retention in rice roots is influenced by cadmium availability, chelation and translocation. Plant Cell Environ. 34, 994-1008. doi: 10.1111/ j.1365-3040.2011.02299.x

Nocito, F. F., Lancilli, C., Giacomini, B., and Sacchi, G. A. (2007). Sulfur metabolism and cadmium stress in higher plants. Plant Stress. 1, 142-156.

Nocito, F. F., Pirovano, L., Cocucci, M., and Sacchi, G. A. (2002). Cadmiuminduced sulfate uptake in maize roots. Plant Physiol. 129, 1872-1879. doi: 10.1104/pp.002659

Noctor, G., Mhamdi, A., Chaouch, S., Han, Y., Neukermans, J., Marquez-Garcia, B. et al. (2012). Glutathione in plants: an integrated overview. Plant Cell Environ. 35, 454-484. doi: 10.1111/j.1365-3040.2011.02400.x

Park, J., Song, W. Y., Ko, D., Eom, Y., Hansen, T. H., Schiller, M., et al. (2012). The phytochelatin transporters AtABCC1 and AtABCC2 mediate tolerance to cadmium and mercury. Plant J. 69, 278-288. doi: 10.1111/j.1365-313X.2011. 04789.x

Rauser, W. E. (1987). Compartmental efflux analysis and removal of extracellular cadmium from roots. Plant Physiol. 85, 62-65. doi: 10.1104/pp.85.1.62 
Rea, P. A. (2006). Phytochelatin synthase, papain's cousin, in stereo. Proc. Natl. Acad. Sci. U.S.A. 103, 507-508. doi: 10.1073/pnas.0509971102

Rea, P. A., Vatamaniuk, O. K., and Rigden, D. J. (2004). Weeds, worms, and more: Papain's long-lost cousin, phytochelatin synthase. Plant Physiol. 136, 2463-2474. doi: 10.1104/pp.104.048579

Rouached, H., Wirtz, M., Alary, R., Hell, R., Arpat, A. B., Davidian, J.-C., et al. (2008). Differential regulation of the expression of two high-affinity sulfate transporters, SULTR1.1 and SULTR1.2, in Arabidopsis. Plant Physiol. 147, 897-911. doi: 10.1104/pp.108.118612

Sghayar, S., Ferri, A., Lancilli, C., Lucchini, G., Abruzzese, A., Porrini, M., et al. (2015). Analysis of cadmium translocation, partitioning and tolerance in six barley (Hordeum vulgare L.) cultivars as a function of thiol metabolism. Biol. Fertil. Soils 51, 311-320. doi: 10.1007/s00374-014-0977-9

Shibagaki, N., Rose, A., McDermott, J. P., Fujiwara, T., Hayashi, H., Yoneyama, T., et al. (2002). Selenate-resistant mutants of Arabidopsis thaliana identify SULTR1; 2, a sulfate transporter required for efficient transport of sulfate into roots. Plant J. 29, 475-486. doi: 10.1046/j.0960-7412.2001. 01232.x

Song, W.-Y., Mendoza-Cózatl, D. G., Lee, Y., Schroeder, J. I., Ahn, S.-N., Lee, Y.-S., et al. (2014). Phytochelatin-metal(loid) transport into vacuoles shows different substrate preferences in barley and Arabidopsis. Plant Cell Environ. 37, 1192-1201. doi: 10.1111/pce.12227

Tabatabai, M. A., and Bremner, J. M. (1970). A simple turbidimetric method of determining total sulfur in plant material. Agron. J. 62, 805-806. doi: 10.2134/ agronj1970.00021962006200060038x

Takahashi, H., Yamazaki, M., Sasakura, N., Watanabe, A., Leustek, T., de Almeida Engler, J., et al. (1997). Regulation of sulfur assimilation in higher plants: a sulfate transporter induced in sulfate starved roots plays a central role in Arabidopsis thaliana. Proc. Natl. Acad. Sci. U.S.A. 94, 11102-11107. doi: 10.1073/pnas.94.20.11102

Verbruggen, N., Hermans, C., and Schat, H. (2009). Mechanisms to cope with arsenic or cadmium excess in plants. Curr. Opin. Plant Biol. 12, 364-372. doi: 10.1016/j.pbi.2009.05.001

Wong, C. K. E., and Cobbett, C. S. (2009). HMA P-type ATPases are the major mechanism for root-to-shoot Cd translocation in Arabidopsis thaliana. New Phytol. 181, 71-78. doi: 10.1111/j.1469-8137.2008.02638.x

Xiang, C., Werner, B. L., Christensen, E. M., and Oliver, D. J. (2001). The biological functions of glutathione revisited in Arabidopsis transgenic plants with altered glutathione levels. Plant Physiol. 126, 564-574. doi: 10.1104/pp.126. 2.564

Yamaguchi, C., Takimoto, Y., Ohkama-Ohtsu, N., Hokura, A., Shinano, T., Nakamura, T., et al. (2016). Effects of cadmium treatment on the uptake and translocation of sulfate in Arabidopsis thaliana. Plant Cell Physiol. 57, 2353-2366. doi: 10.1093/pcp/pcw156

Yoshimoto, N., Inoue, E., Watanabe-Takahashi, A., Saito, K., and Takahashi, H. (2007). Posttranscriptional regulation of high-affinity sulfate transporters in Arabidopsis by sulfur nutrition. Plant Physiol. 145, 378-388. doi: 10.1104/pp. 107.105742

Yoshimoto, N., Takahashi, H., Smith, F. W., Yamaya, T., and Saito, K. (2002). Two distinct high-affinity sulfate transporters with different inducibilities mediate uptake of sulfate in Arabidopsis roots. Plant J. 29, 465-473. doi: 10.1046/j.09607412.2001.01231.x

Zenk, M. H. (1996). Heavy metal detoxification in higher plants - a review. Gene 179, 21-30. doi: 10.1016/S0378-1119(96)00422-2

Zhang, B., Pasini, R., Dan, H., Joshi, N., Zhao, Y., Leustek, T., et al. (2014). Aberrant gene expression in the Arabidopsis SULTR1; 2 mutants suggests a possible regulatory role for this sulfate transporter in response to sulfur nutrient status. Plant J. 77, 185-197. doi: 10.1111/tpj.12376

Zhao, F. J., Wood, A. P., and McGrath, S. P. (1999). Effects of sulphur nutrition on growth and nitrogen fixation of pea (Pisum sativum L.). Plant Soil 212, 209-219. doi: 10.1023/A:1004618303445

Zheng, Z.-L., Zhang, B., and Leustek, T. (2014). Transceptor at the boundary of nutrient transporters and receptors: a new role for Arabidopsis SULTR1; 2 in sulfur sensing. Front. Plant Sci. 5:710. doi: 10.3389/fpls.2014.00710

Conflict of Interest Statement: The authors declare that the research was conducted in the absence of any commercial or financial relationships that could be construed as a potential conflict of interest.

Copyright (c) 2017 Ferri, Lancilli, Maghrebi, Lucchini, Sacchi and Nocito. This is an open-access article distributed under the terms of the Creative Commons Attribution License (CC BY). The use, distribution or reproduction in other forums is permitted, provided the original author(s) or licensor are credited and that the original publication in this journal is cited, in accordance with accepted academic practice. No use, distribution or reproduction is permitted which does not comply with these terms. 